\title{
Effects of solvent on the properties of nano-sized glass powders prepared by flame spray pyrolysis
}

\author{
Jung Sang CHO, Seung Kwon HONG, Dae Soo JUNG and Yun Chan KANG ${ }^{\dagger}$ \\ Department of Chemical Engineering, Konkuk University, 1 Hwayang-dong, Gwangjin-gu, Seoul 143-701, Korea
}

\begin{abstract}
The types of solvent affected the properties of nano-sized Pb-based glass powders prepared by flame spray pyrolysis. The glass powders prepared from the alcohol-free spray solution was $\mathbf{P b}$ rich in comparison with the composition of the spray solution. However, the addition of alcohol to the spray solution decreased the atomic ratio of $\mathrm{Pb}$ to $\mathrm{Si}$ components in the nano-sized glass powders. The addition of ethyl alcohol or methyl alcohol to the spray solution improved the characteristics of the inner structures and transmittances of the dielectric layers fired at a low temperature of $460^{\circ} \mathrm{C}$. The transmittances of the dielectric layers formed from the nano-sized glass powders obtained from the spray solution containing alcohol were higher than $80 \%$ within the visible range at a low firing temperature of $460^{\circ} \mathrm{C}$. However, the transmittances of the dielectric layers formed from the micron-sized and nano-sized glass powders had similar transmittances higher than $90 \%$ in the visible range at the firing temperature of $520^{\circ} \mathrm{C}$.
\end{abstract}

Key-words: Spray pyrolysis, Glass powder, Plasma display panel, Nano powder

[Received October 16, 2007; Accepted December 11, 2007] @2008 The Ceramic Society of Japan

\section{Introduction}

Glass powders are widely used as dielectric layers and fillers in various types of displays and ceramic capacitors. ${ }^{1)^{-5)}}$ Especially, plasma display panels (PDPs) use various types of glass powders for barrier ribs and dielectric layers of front and back panels. In particular, many product applications require glass powders having fine size, spherical shape, narrow size distribution, and homogeneous composition. The new printing process involving ink-jet technology increased the requirement of the glass powders with fine size and regular morphology. However, the glass powders formed by the conventional melting process have irregular morphology and rough surface. ${ }^{6)-8}$

Spray pyrolysis was applied to the preparation of glass powders with submicron size and spherical shape. ${ }^{9)-11)}$ In the spray pyrolysis, the one glass powder was formed from the one droplet by direct melting in the gas phase. The glass powders prepared by spray pyrolysis had good properties as the source powders for transparent dielectric layers. The firing temperature of the glass powders were affected by the mean sizes of the powders. Especially, nano-sized glass powders will decrease the firing temperature. However, nanosized glass powders were not well studied because of difficulty of the production of nano-sized glass powders with homogeneous composition.

Flame spray pyrolysis is different from spray pyrolysis in energy source. ${ }^{12)-18)}$ The high temperature diffusion flame causes melting and evaporation of powders to form the nano-sized ceramic powders. In the flame spray pyrolysis, the types of solvent affect the mean size, morphology, and composition of the nano-sized powders by changing the temperature of diffusion flame. ${ }^{17)-20)}$ Qin et al. showed that flame synthesis using ethanol solution could produce $\mathrm{Y}_{2} \mathrm{O}_{3}$ : Eu nanoparticles with better homogeneity, smoother surface structure and stronger photoluminescence intensity

† Corresponding author; E-mail: yckang@konkuk.ac.kr than using water. ${ }^{18)}$ Chiarello et al. investigated the effect of either alcohols or alcohols + propionic acid mixtures as solvents for the preparation by flame spray pyrolysis of a standard $\mathrm{LaCoO}_{3}$ catalyst. ${ }^{19)}$ Tani et al. investigated the effects of solvent on powder characteristics of zinc oxide and magnesia prepared by flame spray pyrolysis. ${ }^{20)}$

In this study, the well known $\mathrm{Pb}$-based glass powders with a 70 mass $\%$ PbO-20 mass $\% \mathrm{~B}_{2} \mathrm{O}_{3}-10$ mass $\% \mathrm{SiO}_{2}$ composition were prepared by flame spray pyrolysis from the various types of spray solution. The effects of the types of solvent on the properties of the nanometer size $\mathrm{Pb}$-based glass powders prepared by flame spray pyrolysis were investigated.

\section{Experiments}

The volume ratios of alcohol to water were changed from 0 to $20 \%$ to prepare the spray solutions. Ethyl alcohol and methyl alcohol were used as the source of alcohol. The system of flame spray pyrolysis has a droplet generator, flame nozzle, quartz reactor, powder collector, and blower. The detail structure of the flame spray pyrolysis was described in a previous paper. ${ }^{21)}$ A $1.7 \mathrm{MHz}$ ultrasonic spray generator with 6 resonators is used to generate droplets, which are carried into the high-temperature diffusion flame by oxygen, as the carrier gas. Propane as the fuel and oxygen as the oxidizer create the diffusion flame. The flow rates of fuel, oxidizer and carrier gases were each $4.5,35$, and $10 \mathrm{~L} / \mathrm{min}$, in which the length of the diffusion flame was $20 \mathrm{~cm}$. The spray solutions were obtained by adding $\mathrm{Pb}\left(\mathrm{NO}_{3}\right)_{2}$ (Junsei, 99.5\%), $\mathrm{H}_{3} \mathrm{BO}_{3}$ (Kanto, 99.5\%), and tetraethyl orthosilicate (TEOS, Aldrich, 98\%) to distilled water. Clear spray solution was obtained by complete hydrolysis of TEOS using nitric acid. The overall solution concentration was $0.34 \mathrm{M}$.

The crystal structures of the glass powders were studied using X-ray diffraction (XRD) with $\mathrm{Cu} \mathrm{K} \alpha$ radiation $(\lambda=$ $\left.1.5418 \times 10^{-10} \mathrm{~m}\right)$. The morphologies of the glass powders were investigated using scanning electron microscopy (SEM) and energy dispersive X-ray (EDX). The mean size 


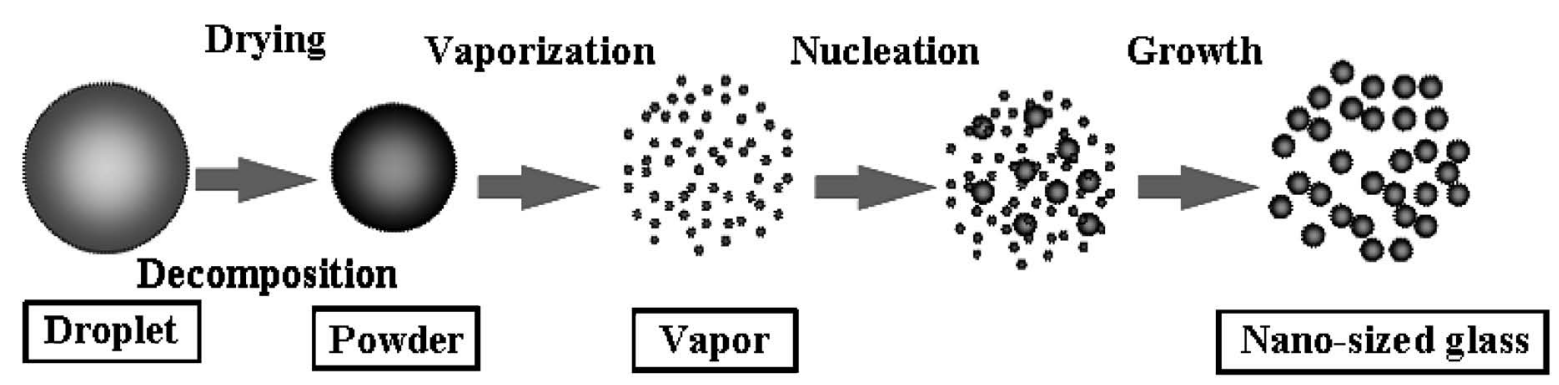

Fig. 1. Schematic diagram of the formation mechanism of the glass powder in the flame spray pyrolysis.

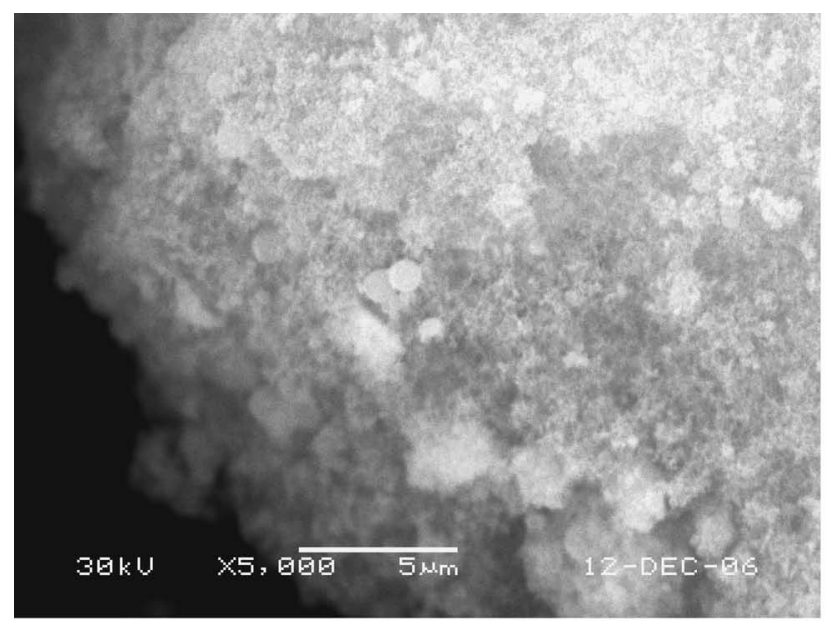

a) Alcohol free

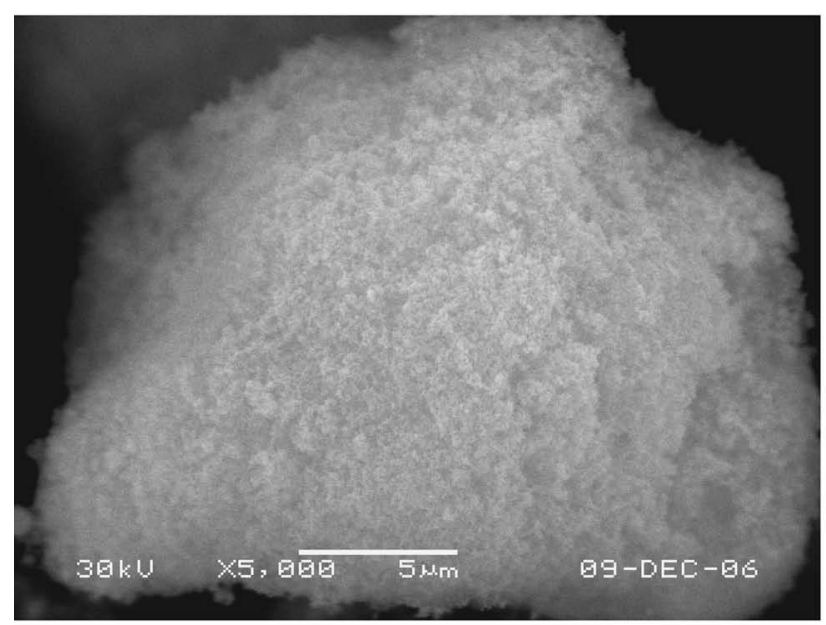

b) EtOH $10 \%$

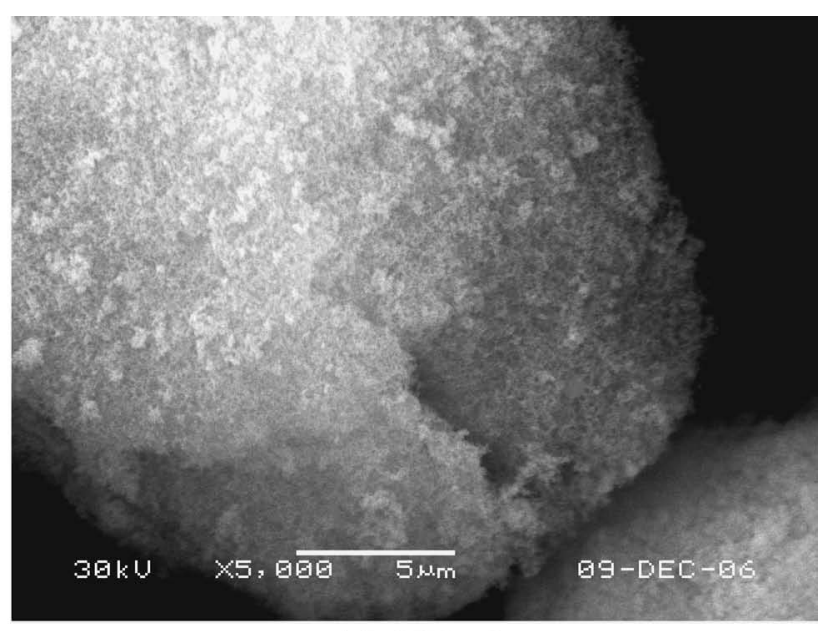

c) $\mathrm{EtOH} 20 \%$

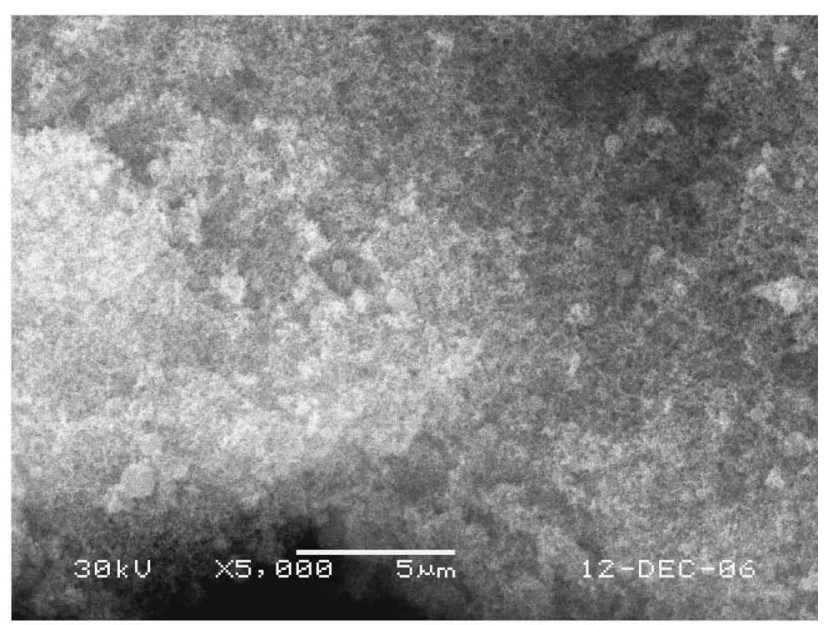

d) $\mathrm{MeOH} 10 \%$

Fig. 2. SEM photographs of the glass powders prepared from the various types of spray solution.

and microstructure of the glass powders were analyzed using transmission electron microscopy (TEM). The transmittances of the dielectric layer formed from the prepared glass powders were measured using a spectrophotometer within a visible light range.

\section{Results and discussion}

The formation mechanism of the nano-sized glass powders in the flame spray pyrolysis was described in the Fig. 1. The temperature of diffusion flame applied in this work was sufficiently high for vaporization of $\mathrm{Pb}$-based glass powders with low volatilization temperature. Therefore, vaporization of the components composing the glass powders occurred inside the high temperature diffusion flame. Nano-sized glass powders were formed from the evaporated vapors by nucleation and growth processes. Therefore, in the flame spray pyrolysis, complete evaporation of the components consisting the glass powders should be occurred to prepare the nano-sized glass powders with appropriate stoichiometry.

Figure 2 shows the SEM photographs of the $\mathrm{Pb}$-based 


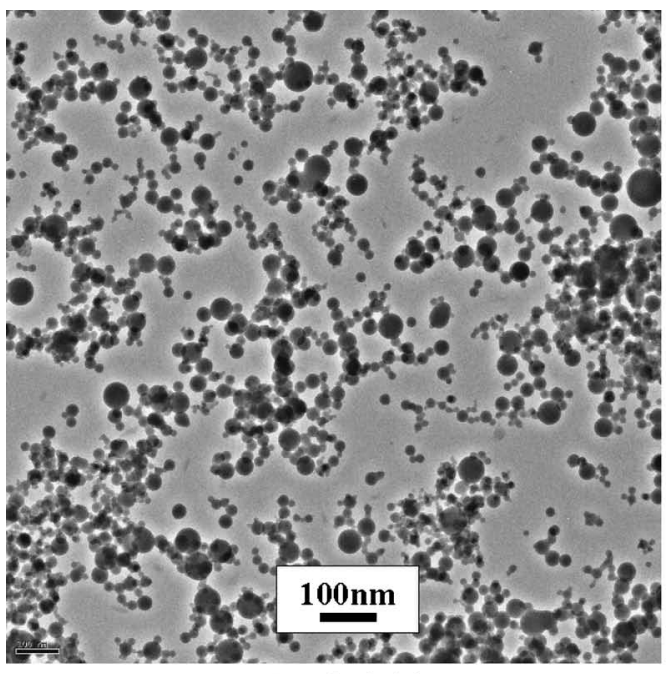

a) Alcohol free

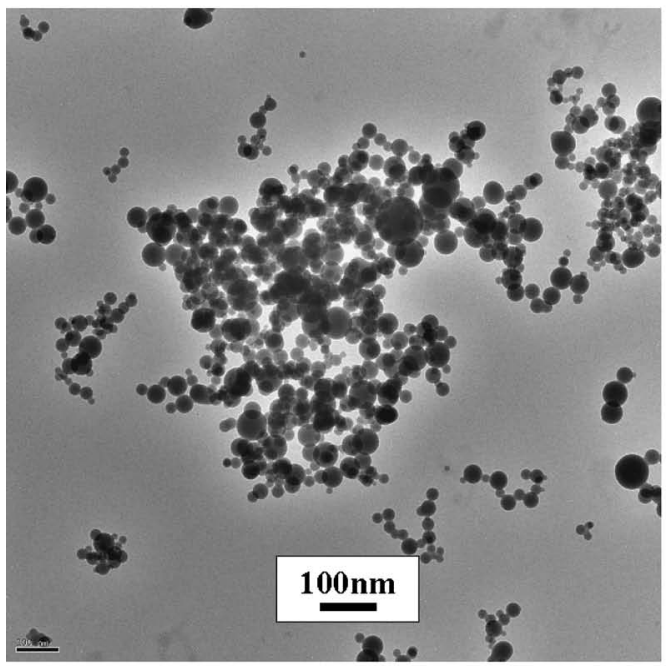

b) $\mathrm{EtOH} 10 \%$

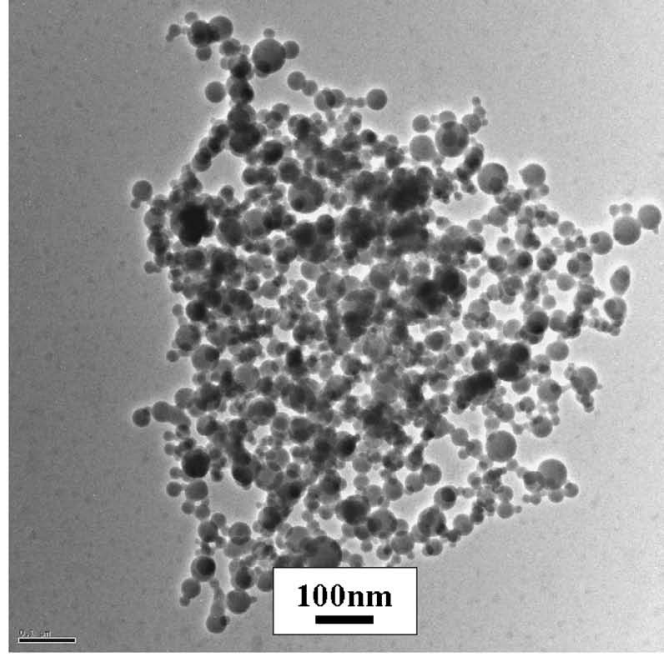

c) $\mathrm{EtOH} 20 \%$

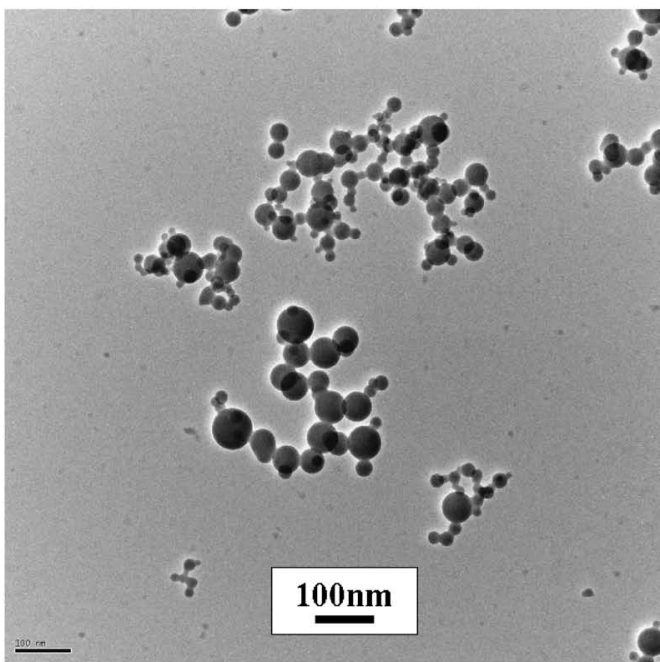

d) $\mathrm{MeOH} 10 \%$

Fig. 3. TEM photographs of the glass powders prepared from the various types of spray solution.

glass powders prepared by flame spray pyrolysis from the spray solutions with various types of solvent. The Pb-based glass powders prepared from the alcohol-free spray solution had bimodal size distribution of nano-sized and submicronsized powders. However, the glass powders prepared from the spray solution with ethyl alcohol or methyl alcohol had monodisperse size distribution and nanometer size. The heat released from the combustion of alcohols provided the high temperature environment which is favorable to nano-sized glass powders synthesis. ${ }^{18)}$ The mean sizes and morphologies of the $\mathrm{Pb}$-based glass powders were investigated from the high magnification TEM photographs as shown in Fig. 3. The prepared glass powders had spherical shapes and nonaggregation characteristics irrespective of the types of solvent. The addition of alcohol into the spray solution slightly increased the mean size of the nano-sized glass powders. The mean size of the glass powders measured from the TEM photograph (Fig. 3(b)) was $39 \mathrm{~nm}$.

The compositions of the nano-sized glass powders obtained by spray pyrolysis were analyzed by SEM-EDX as shown in Fig. 4. The atomic ratios of $\mathrm{Pb}$ to $\mathrm{Si}$ components in the glass powders were described in the Table 1. The atomic ratio of $\mathrm{Pb}$ to $\mathrm{Si}$ components added to the spray solution was 1.88. The glass powders prepared from the alcohol-free spray solution was $\mathrm{Pb}$ rich in comparison with the composition of the spray solution. Incomplete evaporation of silicon component of the large-sized powders produced the nanosized $\mathrm{Pb}$ rich powders. The high temperature of diffusion flame and high evaporation rate of droplets achieved by adding alcohol into the spray solution caused the complete evaporation of $\mathrm{Si}, \mathrm{Pb}$, and $\mathrm{B}$ components. Therefore, the addition of alcohol to the spray solution decreased the atomic ratio of $\mathrm{Pb}$ to $\mathrm{Si}$ components in the nano-sized glass powders.

Figure 5 shows the XRD spectra of the nanometer size $\mathrm{Pb}$-based powders prepared by flame spray pyrolysis from the various types of spray solution. The nanometer size glass powders prepared by flame spray pyrolysis had broad peaks at around $28^{\circ}$ in the XRD spectra, which represent the character of glass materials. The nanometer size glass pow- 


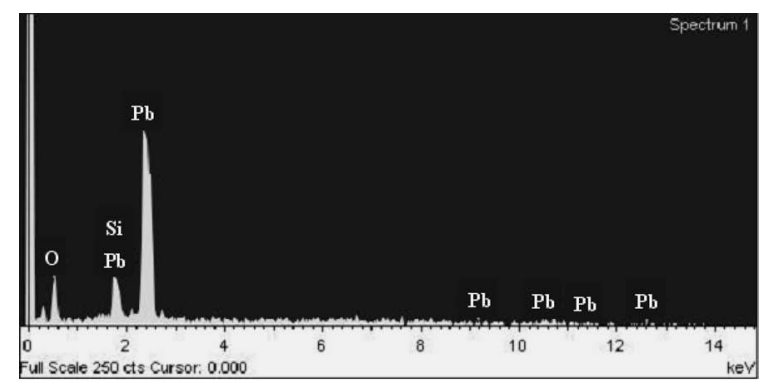

a) Alcohol free

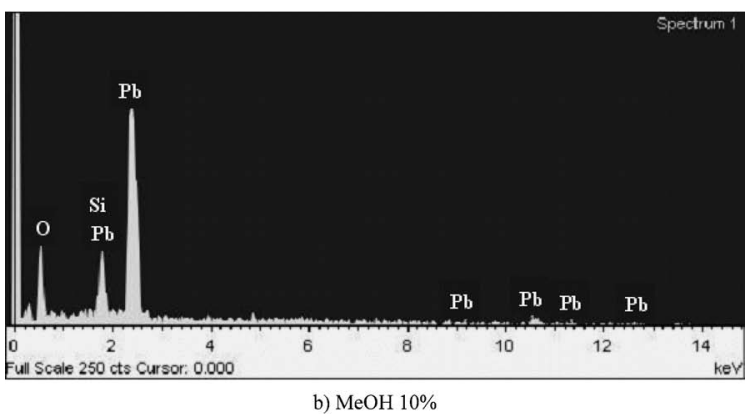

Fig. 4. EDX spectra of the glass powders prepared by flame spray pyrolysis.

Table 1. Atomic Ratio of $\mathrm{Pb} / \mathrm{Si}$ of the Glass Powders Prepared by Flame Spray Pyrolysis

\begin{tabular}{|c|c|c|c|}
\hline \multirow{2}{*}{ Element } & \multicolumn{3}{|c|}{ Powder } \\
\cline { 2 - 4 } & $\mathrm{Si}$ & $\mathrm{Pb}$ & $\mathrm{Pb} / \mathrm{Si}$ \\
\hline Alcohol free & 8.94 & 21.94 & 2.45 \\
\hline $\mathrm{MeOH} 10 \%$ & 7.85 & 16.05 & 2.04 \\
\hline
\end{tabular}

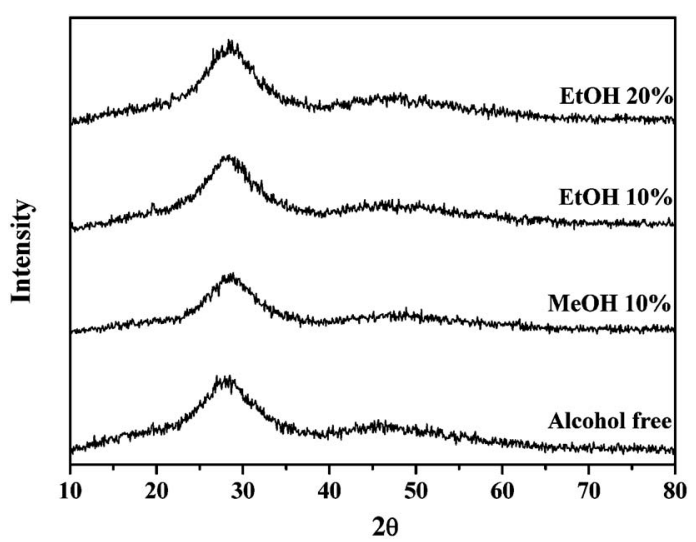

Fig. 5. XRD spectra of the glass powders prepared from the various types of spray solution.

ders with amorphous phases were prepared by flame spray pyrolysis irrespective of the types of spray solution.

The properties of the transparent dielectric layers formed from the nanometer size $\mathrm{Pb}$-based glass powders were compared with those of the layer formed from the micron-sized glass powders. Micron size $\mathrm{Pb}$-based glass powders as shown

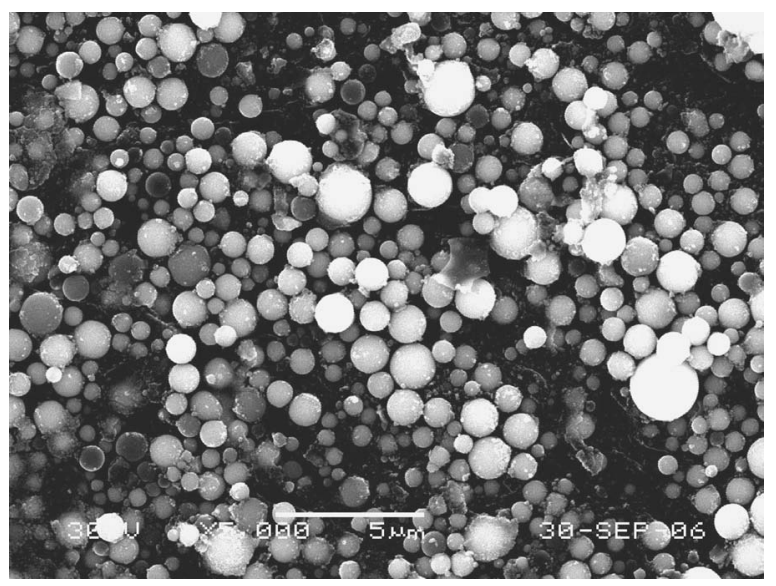

Fig. 6. SEM photograph of the micron-sized glass powders.

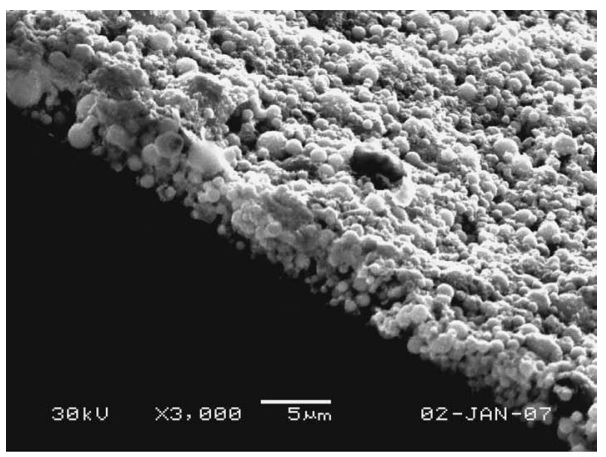

a) Micron size

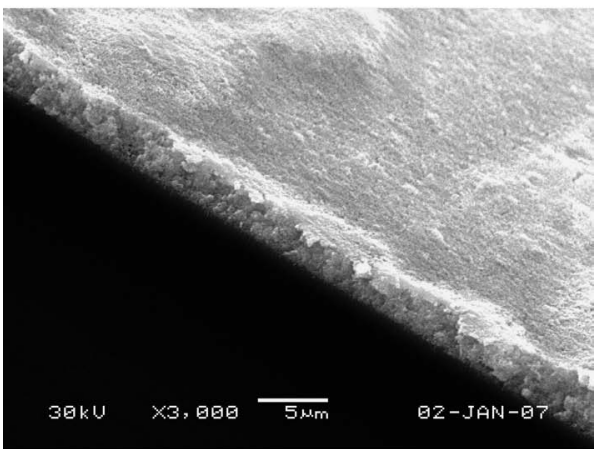

b) Nanometer size

Fig. 7. SEM photographs of the cross-sections of the dielectric layers before firing.

in Fig. 6 were prepared by flame spray pyrolysis at mild preparation conditions. The flow rates of fuel, oxidizer, and carrier gases were each 2,30 , and $30 \mathrm{~L} / \mathrm{min}$. The mean size of the glass powders was $1.7 \mu \mathrm{m}$. The nanometer size $\mathrm{Pb}$ based glass powders prepared by flame spray pyrolysis were mixed with an organic vehicle that consisted of ethyl cellulose, $\alpha$-terpineol, and butyl carbitol acetate (BCA). The glass paste was screen-printed onto the soda-lime glass substrate. The printed glass substrate was dried at $120^{\circ} \mathrm{C}$ for 30 min. The screen-printed glass substrate was fired by 2 steps, at first temperature of $400^{\circ} \mathrm{C}$ for $10 \mathrm{~min}$ at a heating rate of $7^{\circ} \mathrm{C} / \mathrm{min}$ and in the second temperatures between 440 and $520^{\circ} \mathrm{C}$ for $6 \mathrm{~min}$ at a heating rate of $7^{\circ} \mathrm{C} / \mathrm{min}$. Figure 7 shows 


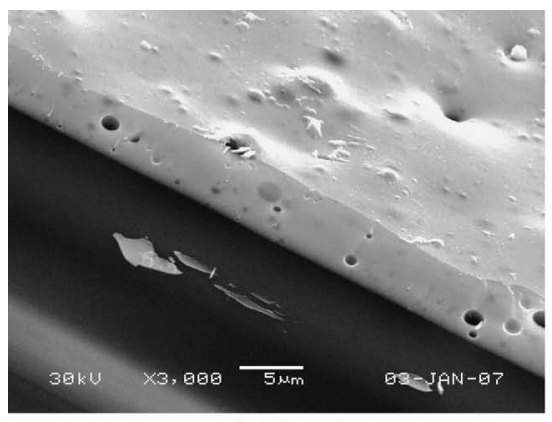

a) Micron size

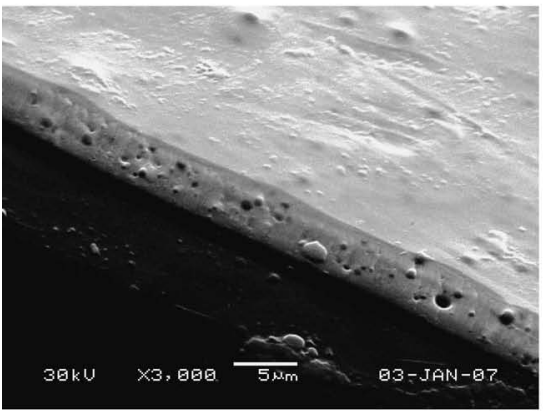

b) Alcohol free

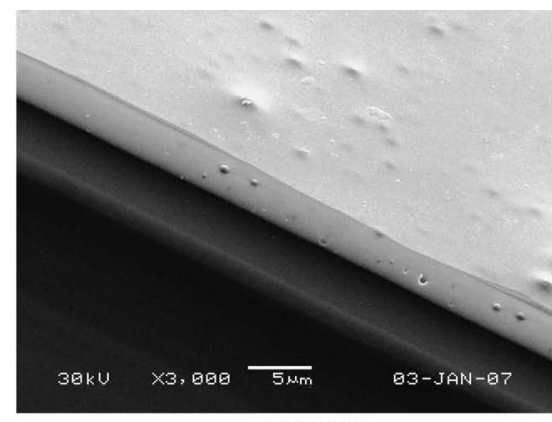

c) $\mathrm{EtOH} 10 \%$

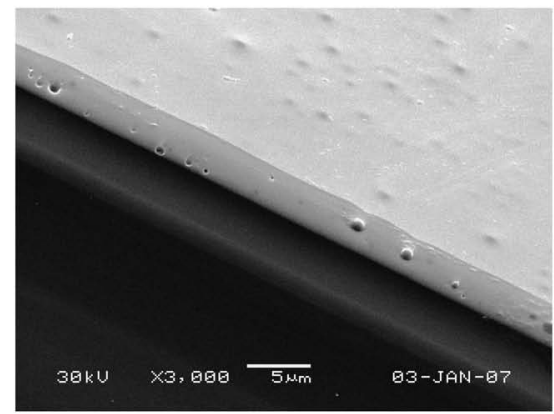

d) $\mathrm{EtOH} 20 \%$

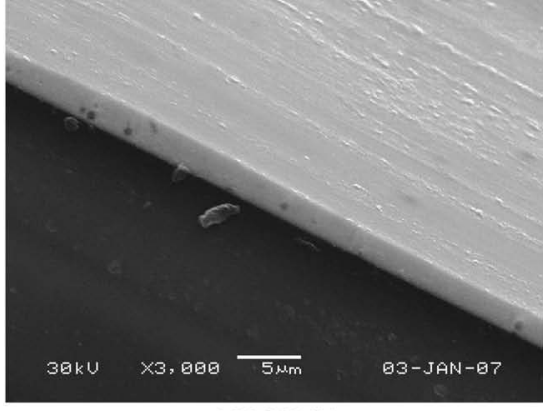

e) $\mathrm{MeOH} 10 \%$

Fig. 8. SEM photographs of the cross-sections of the dielectric layers fired at $460^{\circ} \mathrm{C}$.

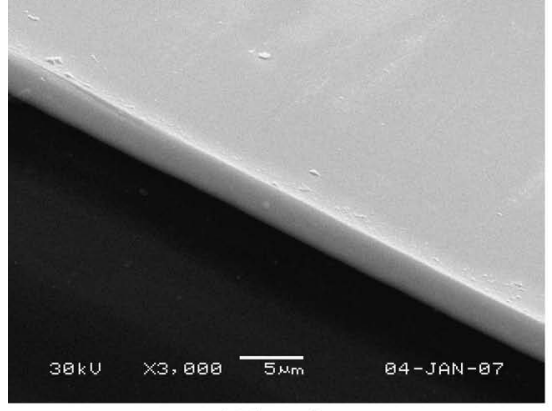

a) Micron size

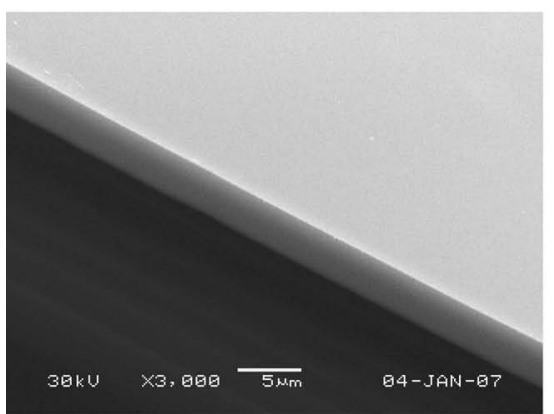

b) Alcohol free

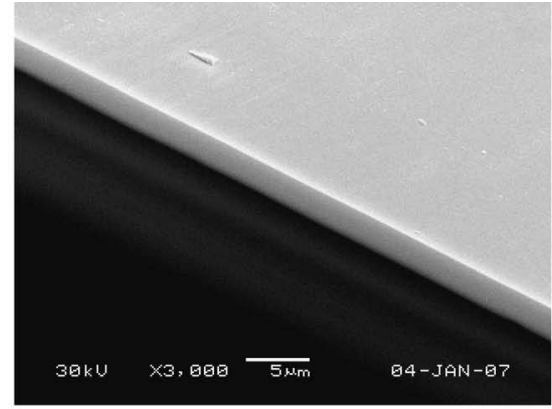

c) $\mathrm{EtOH} 10 \%$

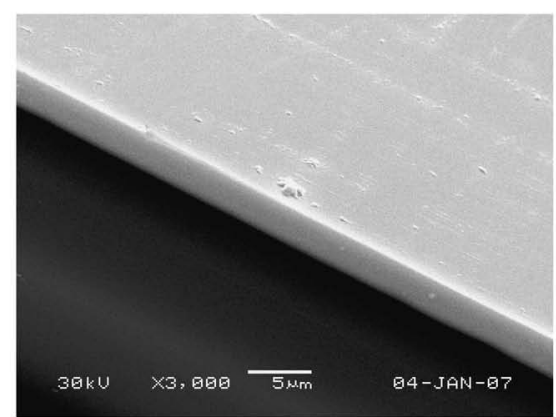

d) $\mathrm{EtOH} 20 \%$

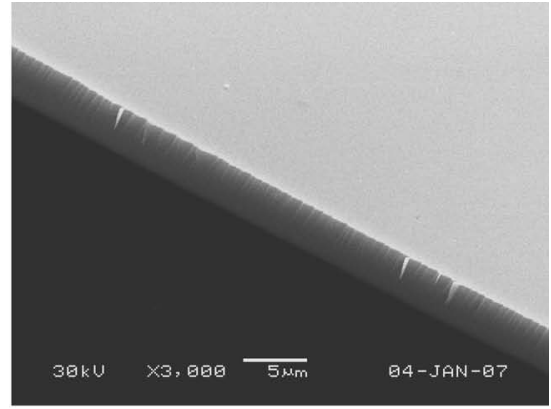

e) $\mathrm{MeOH} 10 \%$

Fig. 9. SEM photographs of the cross-sections of the dielectric layers fired at $520^{\circ} \mathrm{C}$.

the surfaces and cross-sections of the screen printed layers of glass powders. The printed layer of micron-sized glass powders had a number of voids with large size between the powders. On the other hand, the printed layer of nano-sized glass powders had dense structure and smooth surface. Figures 8 and 9 show the SEM photographs of surfaces and cross-sec- tions of the dielectric layers fired at temperatures of 460 and $520^{\circ} \mathrm{C}$. The dielectric layers fired at a low temperature of $460^{\circ} \mathrm{C}$ had different inner structures according to the types of glass powders. The dielectric layer formed from the micronsized glass powders had a number of voids with large size and had rough surface. However, the dielectric layers 


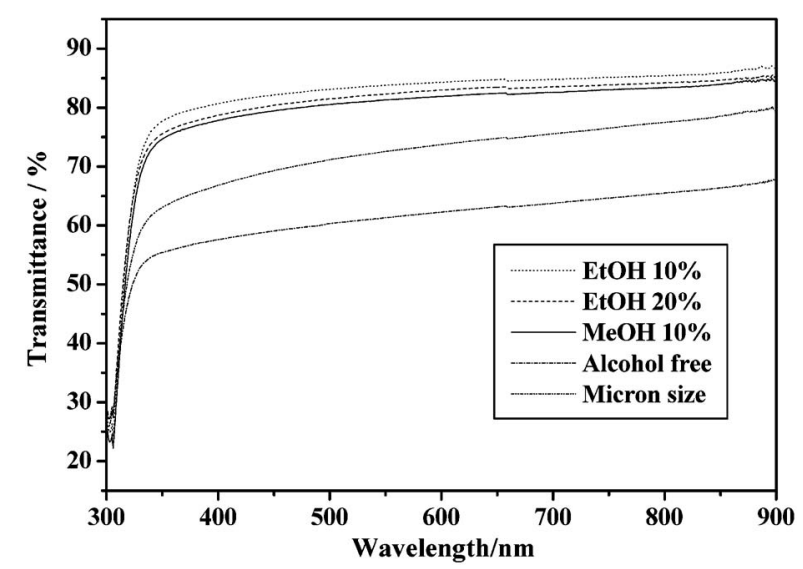

Fig. 10. Transmittance spectra of the dielectric layers fired at $460^{\circ} \mathrm{C}$.

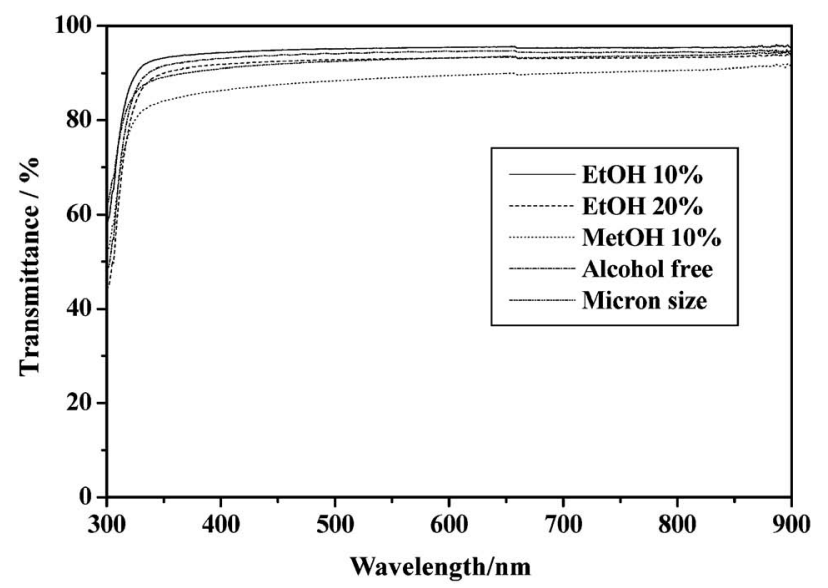

Fig. 11. Transmittance spectra of the dielectric layers fired at $520^{\circ} \mathrm{C}$.

formed from the nano-sized glass powders had voids with small size and had clean surface. The addition of ethyl alcohol or methyl alcohol to the spray solution improved the characteristics of the inner structures of the dielectric layers. The different compositions of the nanometer size $\mathrm{Pb}$-based glass powders affected the inner structures of the dielectric layers fired at a low temperature. The dielectric layers fired at a temperature of $520^{\circ} \mathrm{C}$ had similar inner structures irrespective of the types of solvent. The firing temperature of $520^{\circ} \mathrm{C}$ was enough to obtain the dielectric layers without voids from the $\mathrm{Pb}$-based glass powders obtained by flame spray pyrolysis.

Figures $\mathbf{1 0}$ and $\mathbf{1 1}$ show the transmittances of the dielectric layers formed from the nano-sized and micron-sized glass powders obtained by flame spray pyrolysis. The firing temperatures of the dielectric layers in Figs. 10 and 11 were each 460 and $520^{\circ} \mathrm{C}$. In Fig. 10, the transmittances of the dielectric layers formed from the nano-sized glass powders were higher than $70 \%$ within the visible range. Especially, the transmittances of the dielectric layers formed from the nanosized glass powders obtained from the spray solution containing alcohol were higher than $80 \%$ within the visible range. On the other hand, the transmittances of the dielectric

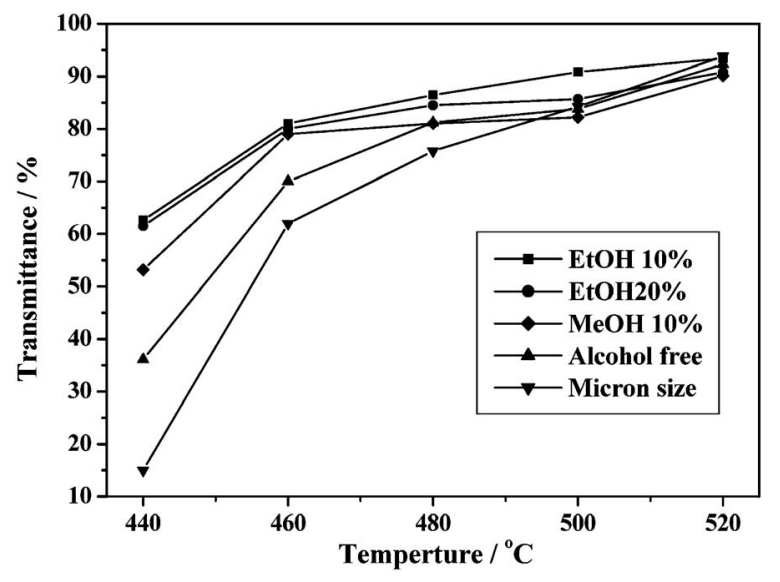

Fig. 12. Transmittances of the dielectric layers fired at different temperatures.

layers formed from the micron-sized glass powders were lower than $60 \%$ within the visible range. The fast firing characteristics of the nano-sized glass powders improved the transmittances of the dielectric layers at a low firing temperature of $460^{\circ} \mathrm{C}$. However, the transmittances of the dielectric layers formed from the micron-sized and nano-sized glass powders had similar transmittances higher than $90 \%$ in the visible range at the firing temperature of $520^{\circ} \mathrm{C}$. Figure 12 shows the transmittances of the dielectric layers fired at different temperatures in the visible light with wavelength of $550 \mathrm{~nm}$. The dielectric layers formed from the nano-sized glass powders had higher transmittances than those of the dielectric layers formed from the micron-sized glass powders. However, the transmittances of the dielectric layers formed from the nano-sized glass powders were affected by the types of solvent. The dielectric layers formed from the nano-sized glass powders obtained from the aqueous spray solution had lower transmittances than those formed from the nano-sized glass powders obtained from the spray solutions containing alcohol at firing temperatures below than $480^{\circ} \mathrm{C}$.

\section{Conclusion}

The characteristics of the dielectric layers formed from the nano-sized glass powders obtained by flame spray pyrolysis were affected by the types of spray solution. The different compositions of the nano-sized $\mathrm{Pb}$-based glass powders obtained from the spray solutions with and without alcohol affected the inner structures and transmittances of the dielectric layers fired at low temperatures. The glass powders prepared from the alcohol-free spray solution was $\mathrm{Pb}$ rich in comparison with the composition of the spray solution. The addition of alcohol to the spray solutions increased the temperature of a diffusion flame. Therefore, the addition of alcohol to the spray solutions decreased the atomic ratios of $\mathrm{Pb}$ to $\mathrm{Si}$ components in the nano-sized glass powders.

\section{References}

1) P. Muralidharan, M. Venkateswarlu and N. Satyanarayana, J. Non-Cryst. Solids, 351, 583-594 (2005).

2) D. N. Kim, J. Y. Lee, J. S. Huh and H. S. Kim, J. Non-Cryst. Solids, 306, 70-75 (2002).

3) H. P. Jeon, S. K. Lee, S. W. Kim and D. K. Choi, Mater. 
Chem. Phys., 94, 185-189 (2005).

4) D. S. Jung, S. K. Hong, J. S. Cho and Y. C. Kang, Appl. Phys. A, 89, 769-774 (2007).

5) S. K. Hong, H. Y. Koo, D. S. Jung and Y. C. Kang, Appl. Phys. A, 85, 63-68 (2006).

6) J. Y. Song and S. Y Choi, Displays, 27, 112-116 (2006).

7) I. Dyamant, D. Itzhak and J. Hormadaly, J. Non-Cryst. Solids, 351, 3503-3507 (2005).

8) S. Morimoto, J. Non-Cryst. Solids, 352, 756-760 (2006).

9) H. Y. Koo, S. K. Hong, S. H. Ju, D. Y. Kim and Y. C. Kang, J. Alloy. Compd., 428, 344-349 (2007).

10) H. Y. Koo, S. K. Hong, I. S. Suh and Y. C. Kang, Mater. Lett., 61, 3669-3672 (2007).

11) H. Y. Koo, S. K. Hong, S. H. Ju, I. S. Suh and Y. C. Kang, J. Non-Cryst. Solids, 352, 3270-3274 (2006).

12) Y. C. Kang, D. J. Seo, S. B. Park and H. D. Park, Mater. Res. Bull., 37, 263-269 (2002).

13) K. Y. Jung and Y. C. Kang, Mater. Lett., 58, 2161-2165
(2004).

14) D. Dosev, B. Guo and I. M. Kennedy, J. Aerosol Sci., 37, 402-412 (2006).

15) A. Camenzind, R. Strobel and S. E. Pratsinis, Chem. Phys. Lett., 415, 193-197 (2005).

16) D. J. Seo, K. O. Ryu, S. B. Park, K. Y. Kim and R. H. Song, Mater. Res. Bull., 41, 359-366 (2006).

17) A. Vital, A. Angermann, R. Dittmann, T. Graule and J. Topfer, Acta Mater., 55, 1955-1964 (2007).

18) X. Qin, Y. Ju, S. Bernhard and N. Yao, J. Mater. Res., 20, 2960-2968 (2005).

19) G. L. Chiarello, I. Rossetti, L. Forni, P. Lopinto and G. Migliavacca, Appl. Cat. B: Environ., 72, 227-232 (2007).

20) T. Tani, A. Kato and H. Morisaka, J. Ceram. Soc. Japan., $113,255-258$ (2005).

21) Y. C. Kang, D. J. Seo, S. B. Park and H. D. Park, Jpn. J. Appl. Phys., 40, 4083-4086 (2001). 